\title{
Research and Application of "Harmony and Contrast" in the Moulding Design of Agricultural Equipment
}

\author{
Wei Chen \\ Jiangsu Open University, Nanjing, China
}

\begin{abstract}
Harmony and contrast is the rule that the agricultural equipment design have to observe. Harmony and contrast of the linear, harmony and contrast of the surface, harmony and contrast of the volume, harmony and contrast of the color, harmony and contrast of material texture, harmony and contrast of line direction, harmony and contrast in the virtual and real relation, and harmony and contrast of the system style are main skill. Correctly handling the relation of harmony and contrast can make the agricultural equipment acquire the vivid and cheery image, and steady heavy, moderate, united result.
\end{abstract}

Keywords—agricultural equipment; moulding design; harmony; contrast

\section{INTRODUCTION}

Aesthetics is a science which studies the existence of beauty, the understanding of beauty, the creation of beauty, that is, natural beauty, social beauty, artistic beauty.

In the study of the aesthetics, the form, color, texture and other factors of ubiquitous in the nature are called formal beauty, which is used to guide industrial product design, to form the aesthetic rule of the product modeling design.

Product design aesthetics rule is gradually formed in the development of human aesthetic history. They mainly are "unity and variety, harmony and contrast, rhythm and rhyme, proportion and scale, stability and portability, symmetry and balance, principal-subordinate and focal point, etc.[1]. It brought great influence to human material life and spiritual life, also have made great progress in society.

Agricultural equipment is an important part of industrial products. It is distributed in vast areas such as farms, ranches and rural areas. It can be directly for serving human production and living on agriculture, fisheries, animal husbandry. Therefore, the research of aesthetic rules has become on of the basic content of the agricultural equipment.

In the aesthetic rules of product modeling, "harmony and contrast" is one of the main rules which has a more important influence on the aesthetic feeling of product modeling.

The black farmland shows distinct strip and block, the shiny green wheat seeding goes with the stream, the heavy rice grain is golden. How harmonious nature gives to farmland and crops. Then, as agricultural equipment, its moulding design should be adapted to the nature, fully reflects the "harmony and contrast" beauty, to be harmony in nature.

\section{HARMONY AND CONTRAST}

Harmony is a kind of transition and connection of using the other elements, when there is a larger difference between two or more elements. It gives a feeling of harmony, softness, stability. Harmony emphasis on generality and consistency [2].

Contrast is to highlight the difference between the elements of identity property, which has significantly different characteristics, to give a lively and vivid feeling. Contrast emphasizes the individuality and the difference[3].

Therefore, the product moulding design must properly handle the relationship between harmony and contrast for different specific image, to make product moulding have both vivid, lively, rich image and stable, coordinated, unify effect.

\section{METHOD OF HARMONY AND CONTRAST}

Main methods of harmony and contrast are harmony and contrast of the linear, harmony and contrast of the surface, harmony and contrast of the volume, harmony and contrast of the color, harmony and contrast of material, harmony and contrast of line direction, harmony and contrast in the relation of false or true, and harmony and contrast of the system style. [1]

\section{A. Harmony and Contrast of the Linear}

Linear mainly refers to the type of object contour which determines its basic shapes, styles and characteristics. There is only two linear, one is straight line, another is curve. They form a contrast. The straight line can be turned into curve, however, the curve can also be turned into a straight line. In the process of their conversion, you can find the harmony between them. As shown in Figure I.

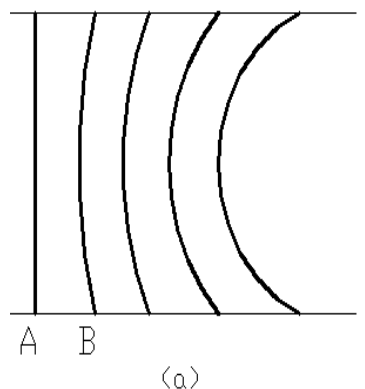

(0)

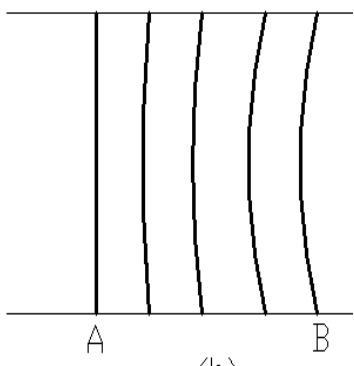

(b)
FIGURE I. HARMONY AND CONTRAST OF THE LINERA 


\section{B. Harmony and Contrast of the Surface}

The surface' size, square and circle, flat and curve can be the factors of harmony and contrast. Generally, you use a gradual and natural transition method as shown in Figure II. Each of the two adjacent surfaces is formed in the gradient, which is both the contrast and the harmony, so as to maintain the mutual relations in the transition.
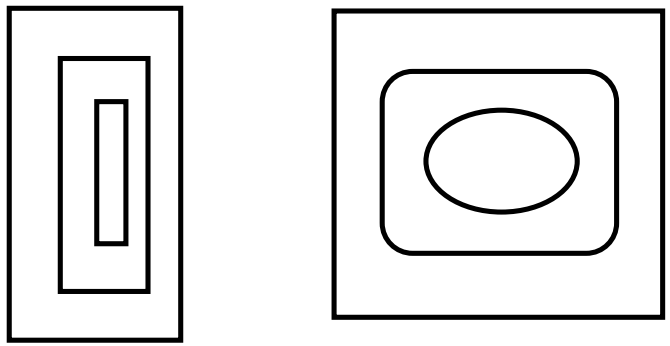

FIGURE II. HARMONY AND CONTRAST OF THE SURFACE

\section{Harmony and Contrast of the Volume}

Any object moulding has a certain volume, occupies a certain space. Only from the consideration the line and surface is not enough, both can only solve the plane problem. So considering volume can solve the problem of three dimensional space.

The use of the law of harmony and contrast and the layout of the various parts of the body can make their volume have an appropriate size, to highlighting the main body, to coordinating overall, as shown in Figure III.

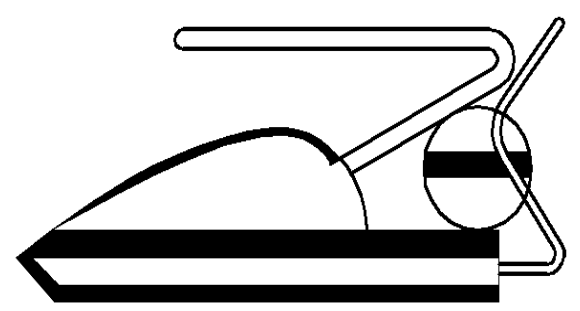

FIGURE III. HARMONY AND CONTRAST OF THE VOLUME

\section{Harmony and Contrast of the Color}

Harmony has common and similar hue on color, such as, bright red, scarlet, purple are harmonious, green, blue and green, blue are harmonious, dark grey, grey, medium grey also are harmonious. Harmony presents unity to soft, elegant feeling; and contrast has obvious different hue on color, such as, red and blue are contrastive.

Using properly color contrast can highlight key, to give products new, pleasing, clear and beautiful visual effect.

\section{E. Harmony and Contrast of Material Texture}

Different materials have different surface texture, the same kind of materials with different processing methods will produce different visual effects.

The forged parts appear rough; the parts machined and treaded by flange appear to be deep; the grinded surface appears light; the surface treated by sandblasting appears stable; etc.

\section{F. Harmony and Contrast of Line Direction}

The contrast of line direction is mainly horizontal and vertical contrast, high and low contrast, centralized and decentralized contrast, etc. Which is used frequently is horizontal and vertical direction. Figure IV is the harmony and contrast of horizontal and vertical direction. Among them, Figure IV (a) and Figure IV (b) are simple vertical and horizontal relations, to give you feel monotonous, dull; Figure IV (c) and Figure IV (d) are some vertical lines in some horizontal lines, to give you feel natural, generous, lively.

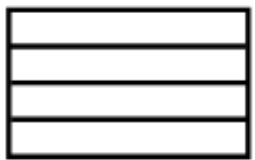

(a)

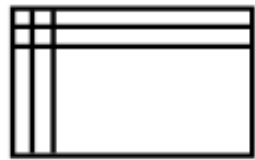

(c)

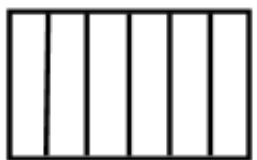

(b)

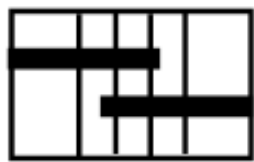

(d)
FIGURE IV. HARMONY AND CONTRAST OF HORIZONTAL AND VERTICAL DIRECTION

\section{G. Harmony and Contrast in the Virtual and Real Relation}

Virtual refers to the transparent or hollow parts of the product. And real refers to the entity part of product. Virtual gives you open, transparent, lightweight feeling, and real gives closed, thick and heavy feeling. Virtual and real relations of harmony and contrast mainly perform convex and concave, empty and solid, sparse and dense, coarse and fine. "real" part usually is focus, depicts the theme; "virtual" part is not the key, plays the role of foil.

\section{H. Harmony and Contrast of the System Style}

In people's daily life. the products are rarely used alone. Whether you design a product or purchase a product, you should consider that the product must be coordinated with natural environment in the overall coordination, and forms contrast in term of the local relations.

This is harmony and contrast of the system style. In the style of harmony and contrast relations, it mainly involves linear style, color style, environmental factors etc.

\section{APPLICATION OF HARMONY AND CONTRAST IN THE MOULDING DESIGN OF AGRICULTURAL EQUIPMENT}

The method of "harmony and contrast" is widely used in the moulding design of agricultural equipment.

Figure V is SNH654 tractor which was developed by Shanghai New Holland Agriculture Machinery Co., Ltd. using the world's technology, which moulding has strong modern sense, and embodies the skill of "harmony and contrast" in many ways. In the linear and surface, the tractor's moulding surfaces are mainly curves and surfaces, it's engine hood, rear fender, cab ceiling etc. are composed of curves and surfaces, 
to form harmony. The front face cab frame, etc. are composed of plane, straight lines, to form contrast; In the color, blue and white form harmony, black and white, blue and orange (steering lamp) form contrast; In the virtual and real[4], when the black walking wheels and the blue engine hood compare with transparent glass windows in the cab, the black tires are real, the cab is virtual, to make you feel that the tires are in the front, fuselage is in the rear, so it is very clear hierarchy. In the volume, when the slender cab frame and the exhaust cylinder compare with a sturdy fuselage and four wheels, they form the contrast of high and low, large and small, coarse and fine, to make the tractor show solid and lively. All of these show that the tractor has a coordinate, generous, resolute, lively, unique moulding style.

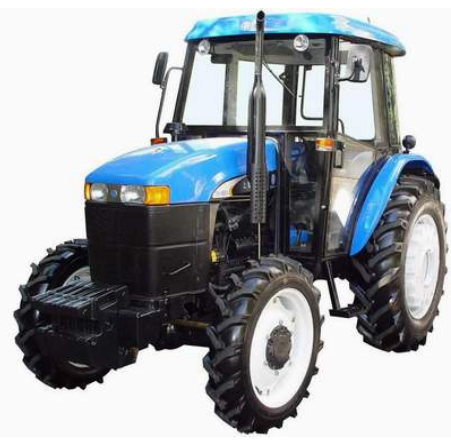

FIGURE V. SNH654 TRACTOR

Figure VI is the half feed combine harvester of the Japanese Yanmar Ce-2 type. In aspects of harmony and contrast have originality. In the linear and surface, the main parts moulding of harvesting table, driving table, unloading grain table etc. are in a straight line, plane surface. They constitute the harmonic unity, and the two sides moulding of unloading grain table are a large arc, which forms contrast. In the color [5] red and white basically each half is very harmonious; and the black walk track as well as chassis and the white form contrast. In the volume, vertical harvesting table itself forms harmonious whole. Compared with driving table, unloading grain table, they form size contrast, to appear lightsome, dynamic; In the direction, the vertical lines on the vertical harvesting table and red, white, black horizontal lines on it formed directional harmony and contrast. All these show that the moulding of the harvester has a mall, lively, clever, unique style.

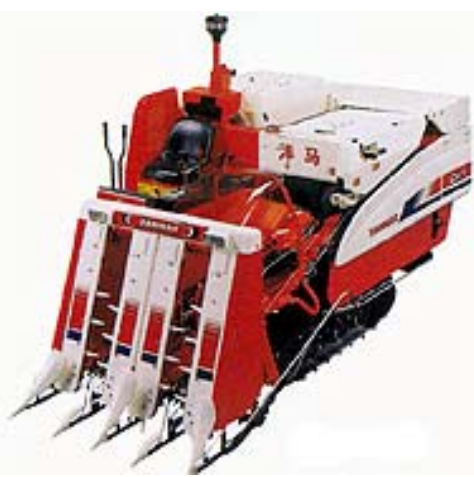

FIGURE VI. A HALF FEED COMBINE HARVESTER OF THE JAPANESE YANMAR CE-2 TYPE
Figure VII is a component of [1] seeder. The upper is a white seed box which material is a light, smooth plastic, the lower is a disc opener which is made of steel plate stamping which material shows a rough, sharp, strong image. Two material's contrast make the component appear stable, firm feeling. In addition, the plane and the surface formed by the harmonic and contrast highlights the visual effect, so that the whole component appears lively and generous.

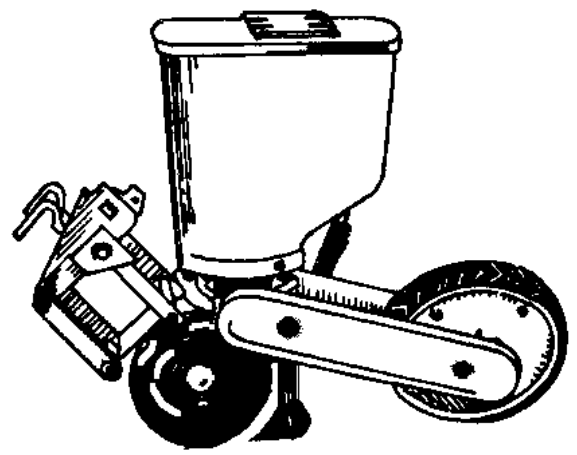

FIGURE VII. A COMPONENT OF SEEDER

Figure VIII is a green forge trailer, it mainly used for transporting livestock feed. The trailer mainly reflected in following aspects of harmony and contrast: the virtual and real, the line direction, the linear and surface. It two sides are made of some rectangular combination to form harmony of linear and surface. And it forms contrast with four round wheels. In the upper part of the fence, some horizontal lines are the main lines, they and some vertical lines form directional harmony and contrast. The linear and surface of middle side panels and upper fences also form harmonious and contrastive relationship. In addition, although the upper part of the fence is very high, it is composed of grids, to give a sense of permeability. That the middle side panels are the entities and the lower dark frame concaves forms the virtual and real contrast. Due to light and loose feed, in order to load more, the trailer is designed to be very tall and big. Nevertheless, the trailer gives you a stable and generous feeling.

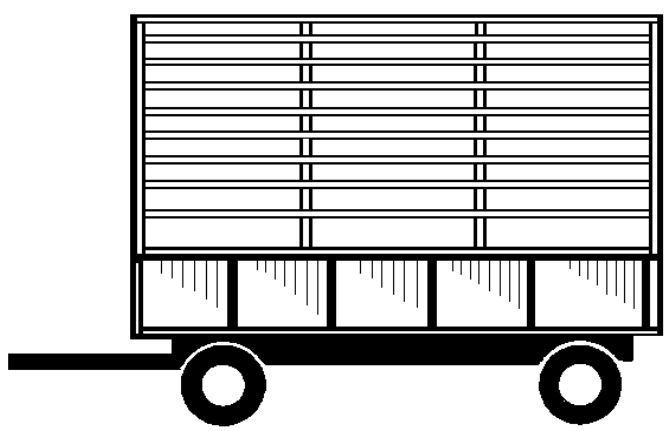

FIGURE VIII. A GREEN TRAILER

\section{CONClusion}

Harmony and contrast is relative. In the same form, the harmonic factor increases, the contrast effect is naturally weakened; Harmonic factor is abate, the effectiveness of contrast is naturally enhanced. In practice, you deal with it according to the different product function and the request. 


\section{ACKNOWLEDGEMENT}

This research was supported by project on institute of education science of Jiangsu Open University (JKY2016A01)

\section{REFERENCES}

[1] Zhen-bang Chen, Agricultural machinery molding aesthetic. Mechanical industry press, 1986:19 46

[2] Wei Chen, Research and application of "harmonic and contrast" farm machinery product modeling design, farm mechanization research, 2013 (4): $26 \sim 29$

[3] Zhi-hao Yu, Mechanical Product Moulding Design. Mechanical Industry press, 1992:77-79

[4] Cheng-qi Xue, Industrial Design Basics. Southeast University Press, 2004: $14 \sim 15$

[5] Chun-ming Han. Industrial product modeling design. Mechanical industry press, 2002:22 24

[6] Duan-yang Geng, The New Agricultural Mechanics. The national defense industry press, 2011.12

[7] Wei Chen. Agricultural Machinery Molding Times Research. Zhenjiang: Jiangsu University, 1991 